\title{
Vulnerabilidad económica y política de la elite criolla del Puerto Rico del siglo XIX ${ }^{1}$
}

\author{
María Margarita Flores Collazo \\ UNIVERSIDAD DE PUERTO RICO
}

A

lo largo de la pasada centuria, en Puerto Rico el gobierno colonial español proveyó de ciertos resquicios de escape, mediante los cuales, los grupos pertenecientes a la elite dominante habían podido satisfacer total o parcialmente sus necesidades económicas. Los privilegios económicos y sociales derivados de las políticas gubernamentales alimentaron cierto sentido de seguridad entre las clases propietarias, lo que era a su vez un requisito esencial para que el gobierno colonial operara con un mí.

${ }^{1}$ Este artículo es una sintesis de algunos de los aspectos tratados en nuestro trabajo "Orden ${ }^{n}, 1991$. nimo de legitimidad y de consenso. Esto último suponía que, los grupos propietarios en general, llegaran a identificar las estructuras de poder estatal como las premisas de orden interno, tanto en sus dimensiones socioeconómicas como institucionales, y de salvaguardia pública y privada. En el caso de los liberales criollos, esa percepción cobraba fuerza en los momentos de apertura liberal del régimen, pues entonces podían conocer de cerca el significado de ejercer alguna influencia en el espacio político provisto para la administración de la colonia.

Ahora bien, el reformismo institucional, aplicado a la isla durante el transcurso del siglo XIX, estuvo orienta- 
do hacia la solidificación de los resortes político-administrativos que fundamentaban el aparato estatal colonial y la creación de efectivas medidas represivas, atribuidas a la intención centralizadora de la metrópoli. Esto dio paso a la elaboración de un sistema de pesos y contrapesos, dirigido a regular y anular los conflictos que la contienda por el poder en la colonia pudiera generar, de manera que quedara garantizada la preservación delorden socioeconómico y político-militar que daba vigencia y legitimación al pacto colonial. A los liberales, la progresiva orientación centralista de la política gubernamental española, les obstaculizó la orquestación de decisiones fundamentales dirigidas a consolidar la inserción de la elite criolla en la dinámica del poder político. Además, el peso del carácter colonial de las estructuras económicas produjo crisis periódicas que, a la larga, tuvieron efectos catastróficos para el desarrollo sostenido de la economía insular. De ahí que, en combinación con la reformulación de los organismos político-administrativos del régimen, la elite liberal criolla propulsara medidas afines con su interés de competir favorablemente en el reparto de la riqueza.

REFORMISMO ECONOMMICO Y CONTROL POLITICO

Hasta la década de 1840, la producción azucarera de Puerto Rico había logrado entronizar, en ritmo ascendente, su dominio en la agricultura de exportación de la isla. La coyuntura favorable para este crecimiento la proveyeron las posibilidades de expansión comercial que ofrecía el mercado mundial (dado el alza de los precios del azúcar determinados en éste); el descalabro de la industria azucarera haitiana; las convulsiones políticas que sacudieron a Europa y a América; la invasión del territorio peninsular por las tropas na. poleónicas y la era de reformas político-administrativas y económicas, aplicadas a la isla entre los años de 1808 y $1815 .{ }^{2}$ Como parte de estas reformas la metrópoli española orientó la agricultura insular hacia el mercado internacional, y constituyó al país en uno capaz de producir influjos económicos al desangrado Tesoro Real.

El clima reformista, impulsado desde la metrópoli, trajoconsigo que en 1810 se reconociera el derecho de las colonias a enviar diputados a las Cortes españolas. A tal efecto, los cabildos de la isla prepararon, como guía de las posiciones que Ramón Power y Giralt (primer diputado puertorriqueño) debía asumir en aquéllas, una serie de instrucciones que reflejaban el interés de la elite criolla (integrada por hacendados, profesionales y pequeños comerciantes) por obtener una mayor participación en el desarrollo económico y en la burocracia administrativa de la colonia. Aun cuando no todas las peticiones fueron consideradas, muchos de los reclamos fueron formalizados en la llamada Ley Power. Entre las reformas de carácter económico implantadas por esta ley, se encontraban la separación de la intendencia respecto a la gobernación; la liberaliza-

\footnotetext{
2 Ramos Mattei, Hactenda, 1986, p. 19; Picó, Historia, 1986, pp. 115-135.
} 
ción del tráfico comercial, particularmente en lo concerniente a la importación de harinas; la exportación de ganado pagando un derecho mínimo; la habilitación de los puertos de Mayagüez, $\mathrm{Ca}$ bo Rojo, Aguadilla, Ponce y Fajardo, y la fundación de la Sociedad Económica de Amigos del País. ${ }^{3}$

Al primer intendente de la isla, Alejandro Ramírez, le correspondió iniciar el programa de reformas económico-administrativas orientadas hacia el fomento de la economía insular y al aumento de los fondos del Tesoro Real. Ramírez reorganizó el sistema impositivo, sustituyendo la variedad de cargas contributivas que pesaban sobre el consumidor, con un impuesto basado en los recursos agrícolas y la productividad del suelo, y descontinuó la práctica de encomendar a particulares la recolección de las rentas. ${ }^{4}$ Además, con el propósito de combatir la crisis fiscal que ocasionó la suspensión en 1810 del envío del situado mexicano a la isla, propuso una nueva emisión de papel moneda y la circulación de la moneda macuquina.

Siendo intendente Alejandro Ramírez, el gobierno metropolitano promulgó para Puerto Rico la Real Cédula de Gracias de 1815. Este documento disponía la entrada, libre de derechos, de maquinarias y aperos de labranza; el comercio libre con España; relaciones comerciales con naciones amigas, in.

\footnotetext{
${ }^{3}$ Silvestrini y Luque, Historia, 1987, pp. 222 . 223; Scarano, Puerto Rico, 1993, p. 380.

4 Sobre los mecanismos fiscales desarrollados por el intendente Alejandro Ramírez, con el fin de promover fondos al Erario Real y mejorar las condiciones financieras de la isla, véase Gonzá. lez Vales, Alejandro, 1978, pp. 9-77.
}

cluyendo Estados Unidos, y la admisión de extranjeros con sus esclavos, caudales y maquinarias. Para beneficio de los nuevos inmigrantes fueron esta. blecidos procedimientos conducentes a legitimar su domicilio en el país y a facilitarles la concesión de terrenos realengos, especialmente si introducían mano de obra esclava. Como consecuencia de esta apertura, la sociedad puertorriqueña fue receptora de un gran influjo de inmigrantes extranjeros y peninsulares procedentes de Europa, de las Antillas Menores y de las convulsionadas colonias hispanoamericanas. Atraídos por las ventajas eco. nómicas ofrecidas por la Cédula de Gracias, muchos de aquéllos lograron adquirir, en corto tiempo, un sólido poder económico, bien como propietarios agrícolas dedicados a la producción azucarera o como comerciantes mayoristas.

El impulso inicial que la economía insular experimentó durante las primeras décadas del siglo XIX, fue observable en la rápida proliferación de haciendas dedicadas al cultivo comercial azucarero por los Ilanos costeros de la isla. Así, en 1820 estaban funcionando alrededor de 1500 haciendas, mientras el volumen de exportación de azúcar registrado demostraba un crecimiento acelerado. ${ }^{5}$ En el término de tres décadas, los pueblos de Ponce, Mayagüez y Guayama (que fueron además los que recibieron el mayor influjo de inmigrantes extranjeros) produjeron la mitad del azúcar destinada para la exportación. ${ }^{6}$ Por otra parte, la mano de obra

\footnotetext{
${ }_{5}$ Ramos Mattei, Hacienda, 1986, pp. 19-20.

${ }^{6}$ Silvestrini, y Luque, Historia, 1987, p. 241.
} 
esclava que trabajaba en estas haciendas también experimentó un aumento notable. Tanto así que, hacia la década de 1830, la población esclava registró un aumento aproximado de $30 \%$, esto sin contar aquellos negros esclavos que entraban de contrabando. ${ }^{7}$ Sin lugar a dudas, a comienzos del siglo XIX la sociedad puertorriqueña vivió una época de apogeo azucarero y es. clavista.

Las medidas aprobadas en el transcurso de las primeras décadas de la pasada centuria, permitieron la inserción de la elite criolla, vinculada con el cultivo comercial de la tierra, dentro del proyecto económico impulsado desde la metrópoli. Sin lugar a dudas, las susodichas reformas dieron paso al fortalecimiento de su posición socioeconómica en el ámbito colonial. De hecho, muchas de sus aspiraciones económicas habían adquirido fuerza de ley, y los beneficios derivados del nuevo programa de reformas se hicieron patentes en corto tiempo.

Ahora bien, la institucionalización de las prácticas comerciales y fiscales de la isla a la luz de una política liberal, no implicó una apertura amplia de los espacios políticos provistos para la administración de la colonia. Es decir, al mismo tiempo que el gobierno español orientaba al sector dominante de la sociedad puertorriqueña hacia la promoción de un cambio económico favorable a sus intereses, adoptaba medidas que limitaran y circunscribieran la participación política de la elite criolla y que excluyeran absolutamente de los procesos de gobierno a las masas.

${ }^{7}$ Ibid., pp. 246-247.
El interés de la elite local por quebrar los obstáculos que impedían su incumbencia en la administración colonial, ya había sido manifestado en las instrucciones que los cabildos habían dado a Ramón Power y Giralt en 1810 . $^{8}$ Más poco ofreció la metrópoli en este sentido. A excepción del establecimiento de la intendencia, se mantuvieron inalterables los poderes discrecionales de los gobernadores y el margen para la representación política de los criollos continuaba siendo sumamente estrecho. Es decir, paralelo al tiempo de la bonanza económica derivada del cultivo y comercialización del azúcar, fue puesto en práctica un rígido control político sobre aquellos grupos sociales cuyas demandas llegaran a cuestionar la legitimidad del orden colonial vigente.

No fue sino hasta la extensión de la Constitución de Cádiz y la consecuente instauración de organismos de poder civil -tales como los ayuntamien. tos clectivos y la Diputación Provincialque el gobierno creó las bases que ampliarían la participación de la elite crio. lla en la administración local. No obstante, dicha participación estuvo sujeta, por un lado, a las luchas políticas surgidas en España entre los promotores de los principios liberales contenidos en la Constitución de Cádiz y las fuerzas defensoras de la monarquía absoluta. El retorno al absolutismo luego de los cortos periodos constituciona. les de 1812-1814 y 1820-1823 significó la negación de los derechos que la Constitución de 1812 había otorgado a la isla, y el retroceso de las luchas de la

8 Consúltese instrucciones en Caro, Power, 1969, pp. 45.128. 
elite criolla por lograr acceso al andamiaje político-administrativo local. Por otro lado, aun cuando la Constitución abría espacios para la competencia de la clase propietaria criolla en los ayuntamientos y en la Diputación Provincial al otorgar a estos cuerpos un carácter electivo, en términos prácticos su participación en los mismos no tenía un alcance político propiamente dicho. El esquema provisto para la organización de los ayuntamientos y de la Diputación Provincial (los cuales, dicho sea de paso, constituyeron los organismos de poder local más preciados para la elite liberal criolla) orientaba sus funciones a aspectos económicoadministrativos exclusivamente, convirtiéndolos así en órganos asesores del gobierno. ${ }^{9}$

La legislación reformista, delineada con el fin de administrar la colonia, revelaba unos rasgos centralizadores tendentes a mantener inalterables los podereś discrecionales de la corona española y sus representantes en el ámbito colonial. De ahí que, por ejemplo, las disposiciones constitucionales confirieron a los capitanes generales las prerrogativas de presidir la Diputación Provincial, de velar por que la corporación cumpliera con sus obligaciones, $\mathrm{e}$ incluso se les otorgó la facultad de destituir a sus miembros. ${ }^{10}$ Por otra parte, el enlace existente entre el régimen provincial y el orden municipal, mantuvo a éste en una relación de depen. dencia respecto al primero. Al mismo tiempo, ambos cuerpos quedaban su163.

${ }^{9}$ González Vales, Alejandro, 1978, pp. 162.

10 Ibid., pp. 179, 182. peditados a la superioridad del poder cívico-militar de la máxima autoridad política colonial y, por supuesto, al poder supremo de la nación.

Frente a la posición planteada por la metrópoli española de regular y controlar el comportamiento político de los funcionarios locales, negando por un lado la concesión de espacios desde los cuales pudieran canalizarse demandas que cuestionaran la legitimidad de dicho poder $y$, por el otro, adscribiendo una política tendiente a otorgar privilegios políticos a los grupos extranjeros y peninsulares que se habían ubicado en posiciones de gran poder económico, la elite criolla mantuvo una actitud crítica (aunque no de desafio) y concurrió en la necesidad de lograr que España reconociera las circunstancias particulares de las Antillas, de manera tal que éstas, manteniendo los lazos de unión con la península, pudie. ran administrar sus asuntos internos. Esta posición se encontraba claramente expuesta en el proyecto que, para el gobierno político-económico de las provincias ultramarinas, presentaran el criollo puertorriqueño José Mariano Quiñones y el cubano Félix Varela, quienes fungían como diputados a Cortes hacia el año de 1823. En dicho proyecto se proscribían las amplias atribuciones concedidas a los capitanes generales y se demandaba la creación de los dispositivos apropiados para la participación de los criollos en los procesos de gobierno. ${ }^{11}$

Sin embargo, el gobierno metropolitano y las autoridades coloniales estaban muy lejos de propiciar la concre-

11 Véase Proyecto, 1823. 
ción de aquellas aspiraciones. En 1823 había vueito a instaurarse el absolutismo, con la consabida abrogación de derechos. En la isla el capitán general Miguel de la Torre fundió nuevamente el poder civil y el militar, además de obtener la concesión de facultades omnímodas en $1825 .{ }^{12}$

Durante su largo mandato (18231837), dicho gobernador se ocupó de hilvanar la rigidez del sistema esclavista con un cerco político sumamente represivo. También emitió un Bando de Policía y Buen Gobierno en el que se prohibía la celebración de reuniones nocturnas en tiendas, almacenes $o$ cafés, y decretó el reglamento de esclavos de Puerto Rico de 1826, que tenía como propósito prevenir posibles conspiraciones y formalizar los castigos infligidos a los esclavos que se sublevaran. ${ }^{13}$ Por otra parte, persiguió con mano dura a todo sospechoso de simpatizar con ideas separatistas, para quienes decretó las penas de prisión o destierro.

Su política represiva se fundamentó sobre hechos reales, pues en Puerto Rico hubo brotes separatistas vinculados con las campañas revolucionarias de las colonias continentales. Además, el arraigo de las ideas abolicionistas en

12 Durante la vigencia del segundo periodo constitucional, las Cortes legislaron para la separación de la capitanía general del gobierno civil de la isla. A tal efecto fue nombrado gobernador civil Francisco González de Linares, y como gobernador militar Miguel de la Torre. Esto quedó invalidado cuando en 1823 éste volvió a fundir en su persona ambos poderes. Silvestrini, y Luque, Historia, 1987, pp. 232-233.

13 Para información más detallada sobre dicho reglamento, véase Baralt, Esclavos, 1981, pp. 67-72.
Ia isla, las rebeliones de esclavos y el aumento de los sectores desposeídos, constituyeron circunstancias atentatorias a la conservación de la integridad nacional y de la paz pública, que además amenazaban el predominio de la economía azucarera esclavista del país. A estos factores se sumaron otros de carácter externo, como por ejemplo el avance del movimiento abolicionista en el Caribe y la presión inglesa a favor del cese del tráfico negrero.

No obstante el ambiente harto represivo creado por las medidas adoptadas por Miguel de la Torre, éste proveyó a las clases propietarias del país de recursos esenciales para el mantenimiento del sistema esclavista del que generaban sus riquezas. Aun cuando en 1820, España había firmado un tratado con los ingleses para concluir con el tráfico de esclavos, en Puerto Rico, Miguel de la Torre auspició el contrabando de esclavos expidiendo permisos especiales a los traficante's negreros para que entraran al país con su cargamento humano libres de mayores perturbaciones. Con esto quedaba minimizado en la isla el problema de escasez de mano de obra, confrontado por los hacendados interesados en explotar comercialmente sus tierras. Por otra parte, con el decreto del Regla. mento de Esclavos, la autoridad colonial ofrecía garantías de protección para los hacendados, tanto en términos de sus personas como de sus propiedades, pues el susodicho reglamento pretendía "proteger a los amos de los abusos de los esclavos".

La acción gubernamental a favor del sostenimiento de la economía azucarera esclavista, hizo que los grupos do- 
minantes de la sociedad puertorriqueña vieran identificados sus intereses económicos con las premisas de orden y seguridad que justificaban aquella acción. Pero la combinación de ésta con una fuerte dosis de control político caía mal al sector criollo de la elite dominante. Si bien la clase propietaria criolla veía con buenos ojos los mecanismos implantados para que no se perturbara el orden interno, difería de las autoridades metropolitanas y coloniales respecto a su intransigencia de no permitirles afirmar, sobre bases sólidas, la legitimidad de su partipación en los procesos de gobierno.

En 1837 fue adoptada para la península una nueva constitución que, para efectos de las posesiones ultramarinas, consignó que en adelante serían gobernadas por leyes especiales. ${ }^{14}$ En ese mismo año, la corona expidió una Real Orden que confería a los gobernadores las facultades que más condujeran a la seguridad del país, al propio tiempo que se les instruía para que redoblasen la vigilancia contra los que aparentaban "apetecer una libertad que no entienden", y que reprimiesen la publicación de escritos que pudieran "perjudicar a la tranquilidad y la seguridad del país, al buen crédito del gobierno español y a la justa causa nacional" ${ }^{15}$

El régimen de especialidad no significó otra cosa que la continuidad de las rígidas restricciones impuestas para mantener el dominio colonial. Reflejo

14 Las constituciones españolas de 1845 y 1856 retiraron el régimen de especialidad para el gobierno de las colonias.

15 Citado por Cruz, Historia, 1952-1979, t. I, pp. 227-228. de esta situación fue el proceso mediante el cual se viabilizó el recorte progresivo de las atribuciones de los municipios, la consolidación de los poderes de los capitanes generales y la articulación de una política represiva capaz de contener, atenuar o suprimir los conflictos que atentaran contra la estabilidad del régimen. Así, en relación con los municipios, se consagró la idea de mantenerlos bajo la continua supervisión del poder central y de garantizar la inserción de los grupos socioeconómicos afectos a la política gubernamental, dentro de las estructuras de poder local. Ejemplo de esto lo ofrecen las leyes municipales que rigieron en los años de 1835, 1846 y 1850.

La ley de 1835 estipulaba que los municipios que tuvieran una población de 100 a 200 vecinos podían formar ayuntamientos. Empero, el gobernador Miguel de la Torre restringió la formación de éstos al tomar en consideración criterios relacionados con la densidad de la población, la riqueza azucarera, la localización adecuada pa. ra fines militares y la antigüedad de la jurisdicción municipal. ${ }^{16}$ Como consecuencia sólo once pueblos lograron establecer ayuntamientos, a saber: Aguada, Arecibo, Aguadilla, Caguas, Coamo, Guayama, Humacao, Mayagüez, Ponce, San Germán y San Juan.

Las bases que dieron forma a la ley municipal de 1835 , fueron ajustadas al impulso que la industria azucarera había tomado durante el primer tercio del siglo XIX. Según señala Cornier López, no fue casualidad que los pueblos

${ }^{16}$ Cornier, "Ley", 1989, p. 35. 


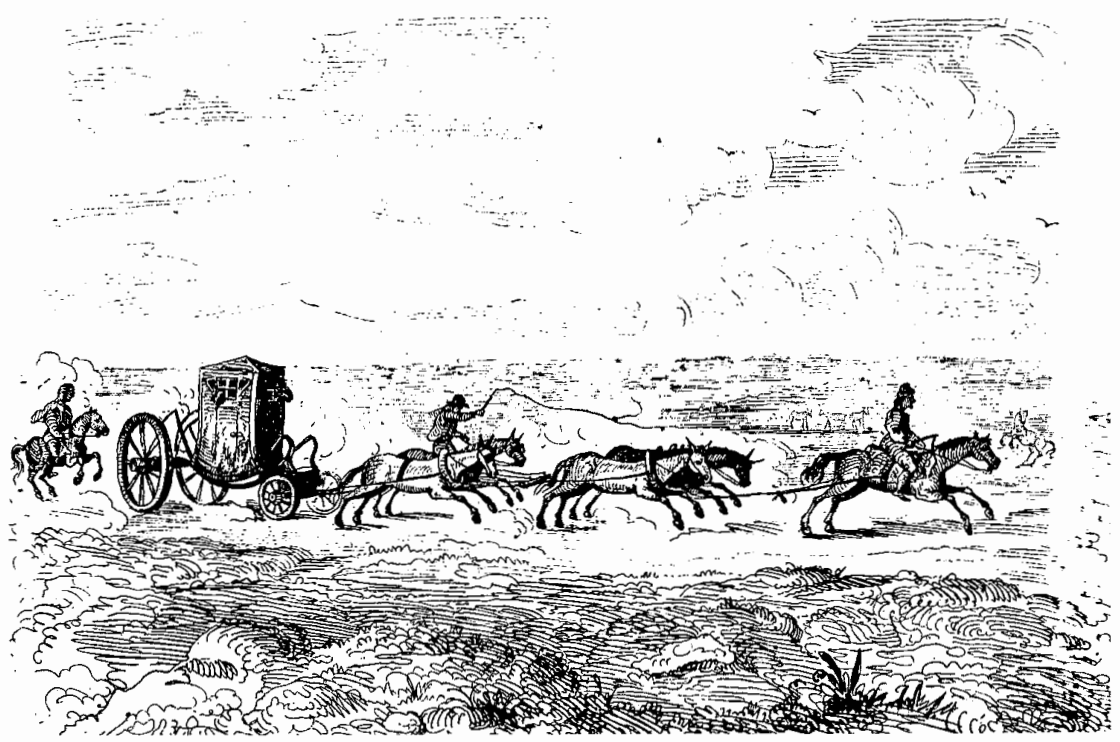

que formaron ayuntamientos fueran aquellos donde se encontraban las principales haciendas azucareras y los puertos habilitados para el comercio. El ordenamiento institucional que se estableció a raíz de dicha ley, estuvo en conformidad con el orden socioeconómico que al gobierno colonial le intere. saba preservar. De esta manera, garantizó la inserción en las esferas de poder local de los miembros (en su mayoría extranjeros y peninsulares) que integraban la capa superior de los sectores vinculados a la economía azucarera.

Con la ley de135, el gobierno insular reforzó la centralización política que fundamentaba el esquema administra. tivo de la colonia. En primer lugar, el establecimiento de los ayuntamientos estuvo bajo el control exclusivo del capitán general. En segundo lugar, los po- cos cabildos que se formaron fueron encuadrados dentro del radio de acción del poder militar. Por otro lado, podemos inferir que desde la perspectiva del gobierno, tales medidas garantizaban que los que ostentaran posiciones de poder en los organismos municipales se mantuvieran dentro de su redil. Es decir, el gobierno proporcionó deliberadamente las condiciones necesarias para que los grupos socioe. conómicos afines con su política pública llegaran a obtener el monopolio de la representación. Pero al mismo tiem. po, precisó los contornos de las esferas dentro de las cuales dichos grupos podian articular sus intereses.

En 1846 la vida municipal insular sufrió un nuevo traspié. En esta ocasión sólo ocho cabildos (Arecibo, Aguadilla, Guayama, Humacao, San Germán, 
San Juan, Ponce y Mayagüez) fueron formalizados. Según lo estipulado por el artículo $4^{\circ}$ del decreto que reorganizaba el régimen municipal, los alcaldes y tenientes de alcaldes eran designados por el gobernador, quedando sus nom. bramientos sujetos a aprobación real. Los demás pueblos estarían regidos por alcaldes corregidores o tenientes de guerra -también de nombramiento oficial- y una Junta de Visita. La capacidad de electores y elegibles para los cuerpos concejiles era reconocida a los mayores contribuyentes de cada localidad. Además, todos los ayuntamientos constituidos eran presididos por el capitán general, mientras las Juntas de Visita se reunían por autorización de éste. ${ }^{17}$

En 1850 el gobernador Juan de la Pezuela restringió a sólo tres el núme. ro de ayuntamientos: los de San Juan, Ponce y Mayagüez. El resto de los municipios continuaba regido por el sistema de Juntas de Visita. ${ }^{18}$ Según Pezue. la, entre las razones que lo motivaron a suprimir los municipios de Arecibo, Guayama, Aguadilla, Humacao y San Germán, se encontraba la necesidad de quitar "a los revoltosos la ocasión de poner en juego sus malévolas intenciones", y daba al gobierno superior de la

17 Consúltese el Real Decreto de 1846 que organiza el régimen municipal de la isla de Puerto Rico y directorto formado para su cumplimiento y efectos sucestvos, Imprenta del Gobierno, Puerto Rico, 1846. Archivo del Consejo de Estado, Madrid (ACE), cartapacio 2, doc. 1 (fotocopia en Centro de Investigaciones Históricas, CIH).

18 "Sobre supresión de varios ayuntamientos en Puerto Rico". ACE, cartapacio 2, doc. 3 (fotocopia en $\mathrm{CIH}$ ). isla "medios eficaces de conservar inalterable el orden y tranquilidad del país". ${ }^{19}$ Para Pezuela su decisión de mantener los ayuntamientos de San Juan, Ponce y Mayagüez quedaba justificada porque, al ser estos tres pueblos los más importantes del país, "había mayor facilidad de encontrar hombres aptos para los oficios concejiles". Dichos municipios eran los centros mercantiles de mayor envergadura en la exportación azucarera; por tanto, constituían los centros de operaciones de los miembros de la capa superior de la elite mercantil y terrateniente, quienes conformaban mayoritariamente el privilegiado estrato de los mayores contribuyentes.

\section{CRISIS DE LA INDUSTRIA AZUCARERA E IMPULSO DE NUEVAS REFORMAS AL RÉGIMEN COLONIAL}

Hacia la década de 1840 , el ritmo de crecimiento de la industria azucarera de Puerto Rico comenzó a decaer como consecuencia del desplome en los precios que causó la sobreproducción de azúcar de mejor calidad en el mercado internacional. Con el avance de la industria del azúcar de remolacha, el azúcar puertorriqueño ocupó una posición desvantajosa dentro de los pará. metros de la economía mundial. Al despuntar en el escenario del comercio internacional un azúcar de fina granulación, los hacendados cañeros de la isla se encontraron subordinados a los

$19 \mathrm{Ibid}$ 
problemas económicos y tecnológicos que conllevaba la exportación de su producto (azúcar mascabado) a un mercado altamente competitivo. En la década de 1840 muy pocos hacendados habían podido introducir mejoras tecnológicas en sus haciendas, como por ejemplo molinos de vapor, los cua. les permitían triturar más caña con mayor rapidez y obtener hasta un $90 \%$ de su jugo. ${ }^{20}$ En parte, esta situación la explica la falta de crédito y capital ne. cesarios para la compra de maquinaria adecuada. Además, los altos impuestos aduaneros sobre las importaciones de maquinaria, después del cese de la Cédula de Gracias en 1836, imposibilitaban todavía más la adquisición de las mismas. Pero aun aquellos que lograron mecanizar parcialmente sus haciendas continuaron produciendo azúcar mascabado, pues las técnicas tradicionales de elaboración se mantuvieron intactas. ${ }^{21} \mathrm{~A}$ las incertidumbres que planteaba el mercadeo a nivel mundial, se sumaba la onerosa política arancelaria impuesta por España, la política de gastos públicos del gobierno colonial, la escasez de crédito y capital, la mengua y eventual desaparición de la mano de obra esclava y la elasticidad de la mano de obra libre.

\section{La política arancelaria de la metrópoli}

La pérdida de las ricas colonias hispanoamericanas significó que España de-

${ }^{20}$ Ramos Mattei, Sociedad, 1988, p. 34 .

21 Ibtd., p. 22 jara de percibir las grandes remisiones económicas con las que aquéllas insuflaban el erario de la metrópoli. A tal efecto, la corona redefinió en el año de 1836 su política económica para con sus colonias antillanas e impuso fuertes impuestos sobre su comercio, lo que trajo consigo que Puerto Rico y Cuba orientaran su producción hacia el mercado norteamericano, donde las barreras arancelarias resultaban menos gravosas. Así, mientras el azúcar de ambas islas pagaba un $30 \%$ a su entrada a Estados Unidos, en el mercado español debían pagar el $50 \%$ de su valor total. ${ }^{22}$ En realidad, Ia preocupación primordial de España era garantizar una fuerte política proteccionista a los productores azucareros de Cataluña y Andalucía, con lo que quedaban desprovistos los azucareros antillanos.

La corona española veía como una amenaza a sus intereses imperiales las relaciones comerciales entre Estados Unidos y sus colonias remanentes. Entonces, como medida previsora, en 1851 impuso un nuevo arancel que aumentaba las tarifas aduaneras sobre el comercio con naciones extranjeras. Como parte del nuevo impuesto, el derecho de importación sobre el azúcar fue duplicado. Esta situación provocó que Estados Unidos adoptara represalias tarifarias contra España y sus colonias antillanas, surgiendo así una guerra de tarifas que caracterizó al resto del siglo XIX y cuyos efectos en Puerto Rico se tradujeron en periodos de agudas crisis económicas.

22 Silvestrini y Luque, Historia, 1987, p. 259. 


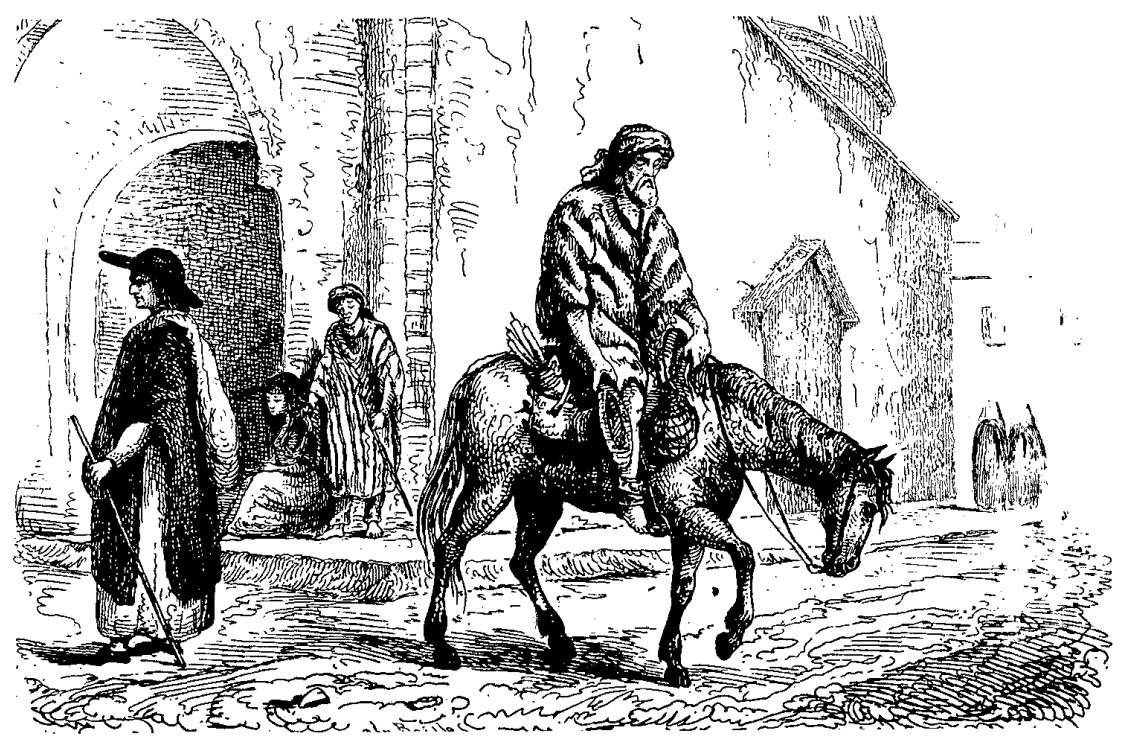

\section{La política presupuestaria del gobierno colonial}

La política de mantener altos impuestos aduaneros, en una economía tan dependiente de los mercados extranjeros, para la importación de artículos de primera necesidad, era imprescindible para garantizar el pago de los funcionarios civiles y militares $y$, por tanto, para fortalecer las relaciones con la metrópoli. De acuerdo con Astrid Cubano, "el empleo público era lo que hacía a la colonia rentable para la metrópoli". ${ }^{23}$ Por consiguiente, el grueso de los recursos financieros del gobierno estaba comprometido con el soste-

23 Cubano Iguina, "Paz", 1990. nimiento del sector no productivo de la sociedad colonial, es decir, la burocracia compuesta de civiles y militares. De éstos, el ejército, tanto en términos de los gastos por concepto de personal como en los referentes al mantenimiento de su infraestructura (plazas de artillería, presidios, etc.), era el que mayor peso económico tenía sobre el erario público. Así, por ejemplo, durante los años de de 1842 a 1846, la Sección de Guerra y Marina del presupuesto insular acarreó un desembolso de 5578581 pesos, es decir, el $65 \%$ de un total de ingresos equivalente a 8577907 pesos. ${ }^{24}$

La fuerte incidencia del ejército y de

24 Esta cifra la extraemos de los datos sum:nistrados por Ormachea, "Memoria", 1981, pp. 413-415. 
la burocracia civil sobre las finanzas del gobierno colonial obstaculizaba las posibilidades de articular una política pública, dirigida a financiar planes de desarrollo que beneficiaran la economía agrícola de Puerto Rico. La agricultura comercial del país tuvo que en. frentarse a los problemas que conllevaba la ausencia de una infraestructura adecuada (caminos, puentes, carrete. ras, instituciones de educación técnica, etc.) para expandir su capacidad productiva y para inyectar vitalidad al comercio local. De ahí que no extrañe que entre las principales demandas de los autonomistas en la década de $\mathbf{1 8 8 0}$ estuviera la reestructuración de los presupuestos coloniales en función del desarrollo de la economía agrícola de las Antillas.

\section{La fuga de capital y la escasez de crédito}

La legislación ordenada por la metrópoli para el régimen del mercado antillano tenía un carácter sumamente extractivo, lo que ocasionaba un continuo drenaje monetario. Una de las válvulas más importantes por donde se escapaba el métalico era la política de intercambio mercantil, desfavorable para la balanza de la isla. ${ }^{25} \mathrm{La}$ falta de reciprocidad comercial con la península alentaba la fuga constante de numerario, pues a cambio de los artículos de consumo que España colocaba pri- vilegiadamente en las colonias mediante tarifas arancelarias, se exigían sólo remisiones en efectivo. ${ }^{26}$ Tal situación acortaba muchas de las expectativas económicas de la gran mayoría de los componentes de la clase propietaria del país, puesto que al no contar con abundante capital líquido, veían limitadas las posibilidades de expandir sus recursos de producción.

Por otra parte, la ausencia de una organización institucionalizada del crédito forzaba a la gran mayoría de los hacendados a depender de los recursos financieros aviados por los comerciantes, a niveles de usura, para la adquisición de los aperos necesarios para el cultivo de las tierras y de otros artículos de primera necesidad. Además, el comerciante ejercía funciones propias de agente de ventas al poner a circular en el mercado los productos agricolas. Apabullados por la falta de excedentes, muchos hacendados no podian cumplir con las deudas contraidas con los que fungían como sus intermediarios, sucumbiendo así a los estragos que producían las crisis cíclicas que afectaban la economía puertorriqueña. Desprovistos de un apoyo gubernamental que los protegiera de las prácticas usureras de los grandes comerciantes prestamistas (en su mayoría peninsulares), muchos hacendados se vieron forzados a cerrar operaciones. A tal efecto, en 1860 el número de ha. ciendas operando se redujo a 550 , del total de 1552 que había en 1830.
25 Cubano Iguina, "Comercio", 1979, p. 12.
26 Ibid. 


\section{El problema de la mano de obra}

A finales de 1840, el sistema esclavista en la isla enfrentaba una serie de problemas que apuntaban hacia su inminente decadencia. Entre ellos estaban el cese del tráfico negrero, el encarecimiento de la mano de obra esclava, las rebeliones de esclavos y el avance de los movimientos abolicionistas en el área del Caribe. En consecuencia, los propietarios azucareros y las autoridades coloniales consolidaron esfuerzos con el fin de regular la afluencia de trabajadores libres a las zonas cañeras. La convergencia de intereses económicos existente entre el gobierno y los hacendados, dio paso a la articulación de un régimen compulsorio de trabajo que "se juzgaba esencial para la prosperidad de la agricultura, el bien de los jornaleros y la tranquilidad públican ${ }^{27}$ A través de la coerción y la implantación de una serie de mecanismos económicos, el poder gubernamental intentaba garantizar mano de obra libre a los hacendados, y de paso fiscalizar la vida de los desacomodados. ${ }^{28}$

Sin embargo, a la larga, el sistema compulsorio de trabajo (institucionalizado con el establecimiento del "régimen de la libreta" por el gobernador Juan de la Pezuela en 1849) no logró resolver el problema de la elasticidad de la mano de obra libre. La ausencia de un flujo constante de capital redu142.

27 Gómez Acevedo, Organtzactón, 1970, p.

28 Un excelente análisis sobre la injerencia del gobierno colonial en la vida del jornalero lo ofrece Fernando Picó en el capítulo V de su libro Libertad, 1981, pp. 115-130. cía las posibilidades de ofrecer jornales que se ajustaran a los altos precios de los alimentos importados. Por tanto, el trabajador libre no tenía un incentivo real para ofrecer con facilidad su fuerza de trabajo. Por otra parte, una actitud de resistencia frente a la coacción ejercida por las autoridades y los propietarios calaba hondo entre los "sin tierra", lo que se traducía en su escasa e irregular participación en las faenas de la agricultura comercial.

A pesar de todos los problemas con los que hubieron de enfrentarse los ha. cendados cañeros, la producción azucarera continuó en curva ascendente; tanto que para 1870 Puerto Rico constituía, después de Cuba, el mayor exportador de azúcar entre los países productores en el hemisferio occidental. ${ }^{29}$ Para ese mismo año, la isla expor tó casi 100000 toneladas de azúcar mascabado, alcanzando el nivel de ex portación más alto del siglo XIX. ${ }^{30}$ Aquellos hacendados que contaron con recursos financieros (en su mayoría extranjeros ubicados en el litoral sur), mecanizaron parcialmente el proceso de elaboración de azúcar; aumentaron la fuerza laboral mediante la adquisición de esclavos y la contratación de jornaleros libres, y expandieron las áreas de cultivo azucarero mediante la absorción de las tierras de los propieta. rios que no pudieron hacer frente a la crisis.

Sin embargo, a partir de los años 70 , aquellos problemas se recrudecieron, lo que produjo que la industria azucarera entrara en un proceso de franca

${ }^{28}$ Ramos Mattei, Hacienda, 1986, p. 26.

29 lbid., p. 28. 
decadencia. La teconología necesaria para producir un azúcar refinada se había vuelto indispensable para compe. tir favorablemente en los mercados de consumo; además, en 1873 se había decretado en la isla la abolición de la esclavitud y del régimen de la libreta. Contando con el dinero que el gobierno les pagaría como indemnización por la pérdida de sus esclavos, muchos hacendados incurrieron en deudas para introducir tecnología más avanzada en sus unidades productoras. No obstante, la compensación fue liquidada 17 años después de la abolición. Con precios bajos en el mercado mundial, con grandes deudas y sin capital, con la pérdida de sus trabajadores, y encima con una metrópoli que se negaba a negociar nuevos tratados comerciales con Estados Unidos, favorables a la industria azucarera de la isla, quedaba totalmente erosionada la capacidad de los hacendados de asentar sobre bases sólidas su posición económica.

Paralelo a las díficiles condiciones que hacian sucumbir la industria azu. carera, en los municipios del interior montañoso tomaba impulso el cultivo y comercialización del café. Con el in. flujo de comerciantes prestamistas en la frontera interna de la isla, surgieron las facilidades de crédito que permitieron a los terratenientes pertrechar sus propiedades con los implementos necesarios para la extensión de las siembras. Además, con el surgimiento de un amplio grupo de campesinos que no pudo ajustarse a los cambios introducidos en el proceso de tenencia de la tierra, se dispuso de un mercado libre de trabajo.

Mientras en la montaña iban creán. dose esas condiciones, en el contexto de la economía mundial se abrieron las puertas para la comercialización del grano puertorriqueño. En las últimas dos décadas del siglo XIX el valor de las exportaciones de café había sobrepasado los niveles de producción y mer. cadeo del azúcar. La alta cotización del grano en los mercados internacionales condujo a que su aportación a la economía de exportación de la isla fuese, en los años de 1886 a 1889, de 5000000 de pesos; para los años de 1890 a 1894 aumentó a 8000000 y de 1894 a 1897 su valor fue de $12000000 .{ }^{31}$ Entre 1890 y 1895, Cuba y España eran los principales importadores del café puertorriqueño, seguidos por Francia, Alemania, Italia y Austria. ${ }^{32}$

El despunte de la economía cafeta. lera y el descenso en el ritmo de crecimiento del comercio azucarero en el transcurso del último tercio del siglo $\mathrm{XIX}$, fueron procesos determinantes de la política pública que orientó al gobierno colonial hacia la década de 1880. Para entonces, el sector azucarero se presentaba incapaz de generar ingresos al tesoro insular. Por tanto, el gobierno se vio en la necesidad de formular un nuevo plan para sostener la solvencia del erario público, de manera que no se viera afectado el mantenimiento de su costoso aparato burocrático cívico-militar.

El nuevo proyecto gubernamental canalizó los intereses económicos de de los pequeños y medianos cafeticultores, de los productores de azúcar mascabado en proceso de contracción

31 Cubano Iguina, Hilo, 1990.

32 Ibid. 
económica, de los productores de frutos de consumo y de los ganaderos. ${ }^{33}$ Con la integración de estos grupos en su proyecto, el gobierno pretendía preservar los vínculos con España, en menoscabo de la creciente dependencia respecto al mercado norteamericano para la exportación de azúcar y la importación de alimentos. El cultivo y comercialización del café, en combinación con un mercado de artículos de consumo local, constituían la base de una relación mercantil estable con la metrópoli. Los cafeticultores encontraban en Cuba y España mercados seguros para su producto, es decir, dentro del circuito comercial del sistema colonial, ${ }^{34}$ mientras la producción para el consumo interno constituía el complemento de las importaciones españolas. Además, de acuerdo con $\mathrm{Cu}$ bano Iguina, los productores de frutos de consumo "dependían de las altas tarifas aduaneras sobre los alimentos importados para mantener sus mercados y los precios altos ${ }^{n} .{ }^{35}$

El plan económico esbozado por los funcionarios coloniales hizo que los sectores azucareros con más posibilidades de expandir sus recursos vieran menguados sus esfuerzos, dirigidos a adelantar su proyecto librecambista. Las opciones librecambistas de am. pliar el mercado a través de la elimina. ción de los altos impuestos aduaneros y la atracción de capital mediante la adquisición de empréstitos en el exte. rior, suponían la disminución de los elevados gastos que ocasionaba la bu.

33 Cubano Iguina, " $\mathrm{Paz}^{\prime}, 1990$.

34 Ibid., p. 34.

35 Ibid.

VULNERABILIDAD ECONÓMICA Y POLITICA rocracia colonial, siendo ésta el principal resorte del régimen de gobierno. ${ }^{36}$

La fuerte oposición expresada por grupos conservadores y reformistas moderados (compuestos de funcionarios públicos y algunos sectores de la clase propietaria) en torno a la reducción de las tarifas aduaneras era, en primer lugar, reflejo de la imperiosa necesidad del gobierno español de mantener inquebrantable su dominio político y económico sobre la colonia. En segundo lugar, proyectaba el interés de los sectores vinculados con la economía de exportación del café, de consolidar la hegemonía económica y la posición social que habían alcanzado desde los tiempos de prosperidad azucarera. Además, manifestaba los intereses inmediatos de los pequeños y medianos cafeticultores y de los cultivadores de frutos de consumo por aprovechar la conyuntura -internacional y local- favorable para la expansión comercial de sus cultivos.

Mientras el sector azucarero se batía con los problemas que agudizaban su vulnerabilidad económica, la elite liberal criolla que integraba parte del mismo continuó su lucha por que España introdujera reformas a las estructuras político-administrativas de la colonia. Sólo una coyuntura amenazadora para los intereses imperiales ampliaría un tanto el margen para la discusión pública de las aspiraciones reformistas de los criollos. Dentro de dicha coyuntura operaron varias circunstancias; entre éstas, la pérdida por España de Santo Domingo en 1865 , luego de un corto periodo de anexión; el triunfo de los

${ }^{36}$ Ibtd., pp. 104-105. 
movimientos antiesclavistas en Estados Unidos; las crecientes presiones de Inglaterra y los abolicionistas en Europa y A mérica, y la acuciante política expansionista del gobierno estadunidense. Esta convergencia de factores puso sobre el tablero la necesidad de redefinir los fundamentos del régimen colonial. A tal efecto, el ministro de Ultramar, Antonio Cánovas del Castillo, convocó en 1865 a representantes de Cuba y Puerto Rico para que informasen sobre las bases en que debían descansar las prometidas leyes especiales.

En 1866 se inauguró la Junta Informativa de Ultramar en Madrid. En términos políticos, el informe de la comisión, integrada por liberales cubanos y puertorriqueños, formuló los fundamentos del régimen gubernamental a la luz de los derechos constitucionales que disfrutaban los españoles de la península. Además, consignó la proscripción de la política centralista y arbitraria ejercida por los capitanes generales. Como base de un nuevo orden político de carácter autonomista, puntualizó la necesidad de reorganizar los ayuntamientos electivos y el gobierno general de la isla, este último compuesto por una diputación provincial y un consejo insular.

Después de celebrar 36 sesiones, la Junta Informativa fue clausurada sin que los representantes antillanos lle. garan a conseguir ninguno de sus propósitos. No obstante, es necesario destacar la importancia de sus manifestaciones. En este sentido debemos señalar que, si bien la gama de los asuntos tratados por aquélla no constituyó un desafio a la legitimidad del orden colonial, sí reflejó el deseo de fundamentar las bases de las relaciones coloniales sobre el principio de un gobierno propio, adoptado de forma congruente con las aspiraciones políticas de la elite criolla.

Con el triunfo de la revolución gloriosa en España (1869) y la instauración de la primera república española (1873), se creó un clima favorable para la implantación de un régimen político más representativo en las colonias. En el transcurso de ese periodo los liberales españoles optaron por restituir a las provincias ultramarinas el derecho de representación a Cortes. En Puerto Rico se dio paso a la modernización de la vida política mediante la fundación de partidos políticos; la extensión a la isla de algunos de los derechos constitucionales que regían en la península -como por ejemplo los derechos de reunión y de prensa-; el restablecimiento de la diputación provincial; la organización de ayuntamientos con una base más amplia para la participación local, etc. De ahí que las reformas impulsadas por el gobierno liberal metropolitano, significaran para los liberales criollos la posibilidad de llevar a cabo sus acciones dentro de un relativo margen de legitimidad. Esto estimuló su tendencia a tratar de adaptar las estructuras del régimen colonial a su interés por expresar en términos políticos sus necesidades económicas y, por ende, de ensanchar sólidamente su participación en la vida pública del país.

Pero las reformas implantadas por los liberales septembrinos para la administración del Estado nacional fue. ron aplicadas a la colonia con notables 


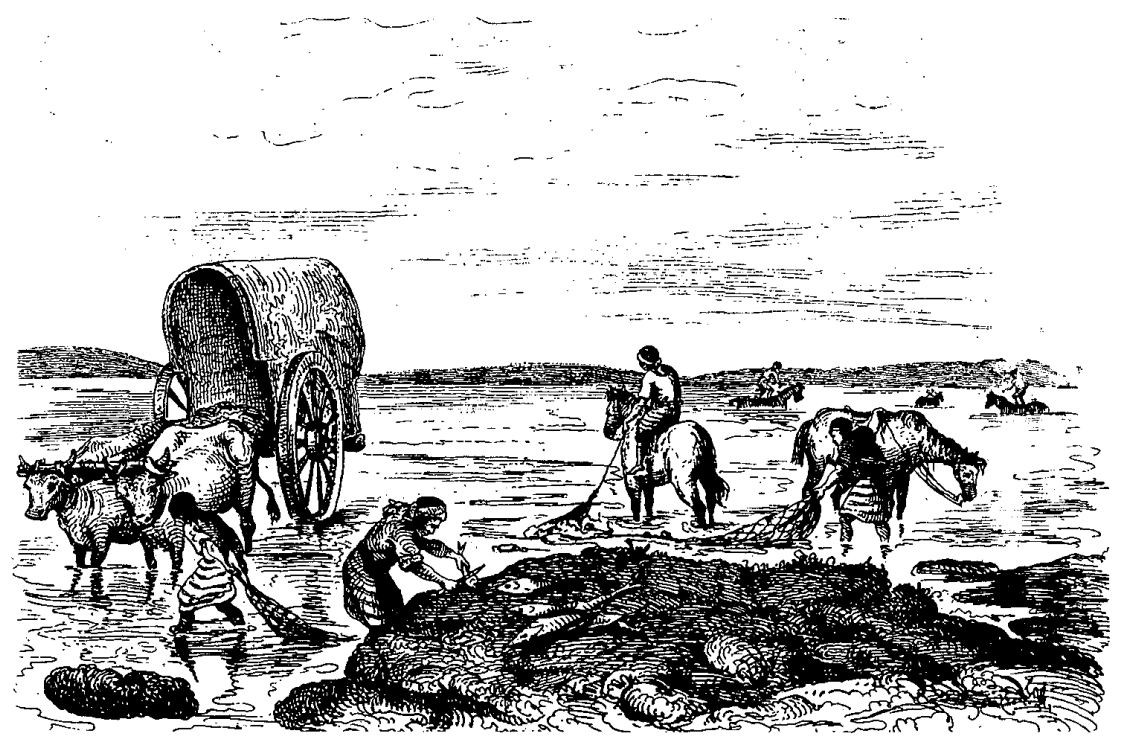

modificaciones. Según el Ministerio de Ultramar, la distancia y las circunstancias especiales del país precisaban una concentración más vigorosa del poder central. Para el gobierno metropolitano, la extensión a Puerto Rico del título I de la Constitución de 1869, que consagraba los derechos políticos de los ciudadanos españoles y la abolición de la esclavitud, podía suscitar enconos y conflictos contra los intereses nacionales. A tal efecto, demandó de la máxima autoridad colonial que estu. diara "detenidamente la conveniencia de acelerar o retrasar las reformas políticas que la república ha de llevar a ultramar". ${ }^{37}$

37 "Minuta del Ministerio de Ultramar al gobierno superior civil de Puerto Rico", Madrid,
El reformismo institucional aplicado a la colonia por los líderes del sexe. nio revolucionario, estuvo marcado por una política más concesiva. No obstante, las previsiones no podían faltar. Al tiempo que se concedió espacio para la representación política de la sociedad colonial, mediante la organización de partidos políticos y la apertura de canales institucionales en los que podría articularse una lucha legítima por el poder, la metrópoli estructuró un conjunto de medidas dirigidas a prevenir el desarrollo de una actividad política al margen del control del gobierno colonial. Así, por ejemplo, las

13 de abril de 1873. Archivo Histórico Nacional (AHN), Ultramar, leg. 5113, exp. 21, doc. 1 (mic. en $\mathrm{CH}$, carrete 190). 
funciones de la Diputación Provincial continuaron ciñéndose a las de orden económico-administrativo pues, por prohibición expresa de la ley, sus integrantes no podian discutir ni proponer ninguna medida política. Por otra parte, con el propósito de encuadrar el radio de acción del poder ejecutivo dentro del esquema centralista provisto para la administración de la colonia, las autoridades metropolitanas expidieron, el 28 de agosto de 1870 , un decreto orgánico que facultaba a los gobernadores para suplir por sí mis. mos o por sus delegados las acciones y funciones de la Diputación y de los ayuntamientos. ${ }^{38}$

En el transcurso del último tercio del siglo XIX, las crecientes demandas de los liberales para obtener un mayor acomodo dentro de las estructuras políticas del gobierno, encontraron fuerte resistencia de parte de gobernadores como José Laureano Sanz. ${ }^{39}$ Bajo su mandato el poder gubernamental fue vigorizado y la ocupación militar de la colonia fue fortalecida. Sanz elaboró y ejecutó una serie de mecanismos dirigidos a hacer de los organismos de poder local verdaderos gestores de la vo. luntad oficial. Esto lo logró mediante persecuciones a miembros del Partido Liberal, decretos dirigidos a acallar la impugnación del régimen o a restringir la participación electoral de quienes

38 Sobre este particular, consúltese "Gobierno general de la isla de Puerto Rico. Ministerio de Ultramar. Exposición a su majestad", en Gaceta de Puerto Rico, 18 de junio de 1878. AHN, Ultramar, kg. 5110 , exp. 11, doc. 3 (Mic en CIR, carrete 180)

39 José Laureano Sanz gobernó en Puerto Rico durante los años de $1868-1870$ y 18741875 . consideraba separatistas solapados. Pero el legado más importante que Sanz dejó a sus sucesores fue la estructuración de un sistema militarizado de seguridad interior, cuyos elementos constitutivos (Guardia Civil, Cuerpo de Voluntarios y Cuerpo Municipal y de Orden Público) fueron instrumentos armados creados para extender la irradiación del poder central, y cuyas ejecutorias estuvieron en función de la política de contención social del gobierno colonial. ${ }^{40}$

La caída de la primera república española (1874) y la consiguiente restauración del gobierno monárquico en España, significó para Puerto Rico la consolidación del poder enérgico y represivo del gobierno. El ambiente no podía ser más aciago para la abierta pronunciación de reformas al régimen de gobierno. Hasta la década del 90, la regulación de la prensa, por ejemplo, exhibió una vinculación sumamente estrecha con la política gubernamental de cercenar al movimiento liberal. Sin embargo, la opinión liberal no cejó en su empeño de hacerse sentir. Aun bajo las restrictivas reglamentaciones a las que era sometido el derecho de expresión en el país, los liberales criollos expusieron su ideario a favor de la descentralización económicoadministrativa dentro de la unidad nacional. ${ }^{41}$ Hacia la década de los 80 , las aspiraciones políticas de los liberales criollos se definieron abiertamente a favor de la autonomía colonial, y en el año

40 Véase Flores Collazo, "Orden", 1991, pp. $120-178$

41 Para un estudio amplio sobre la trayectoria del pensamiento autonomista puertorriqueño en el siglo xIx consúltese, Barbosa, Baldorioty, 1974; Náter "Autonomismos", 1991. 
de 1887 fundaron el Partido Autonomista Puertorriqueño, en Ponce. ${ }^{42}$

Para aquel entonces, el país enfrentaba una de sus crisis económicas más graves como consecuencia del desplome de la economía azucarera. Una de las manifestaciones de los conflictos provocados por la crisis y por la negativa del gobierno para implantar medidas que atajaran su creciente agudización, fue el surgimiento de un movimiento dirigido a socavar el poder económico de aquellos que controlaban las redes del comercio insular. A lo largo de la década de los 80 se propaló la idea, entre los sectores autonomistas más rádicales, de boicotear los establecimientos de los dueños o socios de poderosas firmas comerciales, identificados como españoles sin distingos. ${ }^{43}$

Además de los objetivos económicos de las sociedades que se organizaron para boicotear los negocios de los peninsulares, aquéllas contenían obvios ribetes políticos. Como señalamos

42 No fue hasta el año de 1882 que en Puerto Rico los partidarios del liberalismo pudieron discutir sus principios autonómicos dentro de un marco de legalidad. En ese año, la Audiencia de Puerto Rico absolvió a los firmantes de un manifiesto que proclamaba la candidatura para diputado a Cortes de Rafael María de Labra, reconocido propulsor de la causa autonomista. Esto se debió en parte al precedente establecido en 1881 por el Tribunal de Imprenta de Cuba, cuando declaró compatible la doctrina autonomista con la Constitución española de 1876. Esta situación, sin embargo, no significó la eliminación de la política de censura que encajonaba la libertad de expresión en el contexto colonial. 128.

43 Cubano Iguina, "Estudio", 1988-1989, p.

VULNERABILIDAD ECONÓMICA Y POLITICA anteriormente, los seguidores más radicales del credo autonomista fueron los que originaron el movimiento del boicot. Pero también, el tono político que las marcó tuvo su origen en la forma en que fueron percibidas por las autoridades y sus adeptos incondicionales. Éstos las tacharon de asociaciones ilícitas con fines conspirativos, lo que dio fuerza de ley a la persecución desencadenada contra el autonomismo y sus posibles simpatizantes durante lo que se conoce, en la historia de Puerto Rico, como el terrible año del 87. En el transcurso de los meses de agosto y noviembre de dicho año, el gobierno colonial puso de manifiesto su naturaleza coactiva de la manera más pura. La persecución, el encarcelamiento y la tortura constituyeron parte de las ejecutorias de las fuerzas paramilitares creadas en el último tercio del siglo XIX. Particularmente, la Guardia Civil se exhibió como el brazo político armado más eficaz del gobierno y de los caudillos locales. ${ }^{44}$

No obstante la deleznable rudeza de las acciones coactivas ocurridas en 1887 , el gobierno no pudo suprimir las aspiraciones autonomistas. A pesar del régimen de silencio que reinó luego del amargo trance vivido, la lucha reformista persistió. Tanto así, que en la década de los 90 volvió a romperse el silencio, y dentro de las propias estructuras gubernamentales se abrió un espacio más responsivo a los requerimientos reformistas.

44 Véase Flores Collazo, "Orden", 1991, pp. 206229. 


\section{BIBLIOGRAFIA}

-Baralt, Guillermo, Esclavos rebeldes. Conspiraciones y sublevactones de esclavos en Puerto Rico (1795-1873), Ediciones Huracán, Río Piedras, 1981.

- Barbosa de Rosario, Pilar, De Baldorioty a Barbosa. Historia del autonomismo puertorriqueño, Imprenta Venezuela, San Juan, $2^{\mathrm{a}}$ ed., 1974.

-Barceló Miller, María de F., Política ultramarina y gobierno municipal: Isabela, 1873-1887, Ediciones Huracán, San Juan, 1984.

-Caro Costa, Aída, Ramón Power y Giralt. Diputado puertorriqueño a las Cortes Generales y Extraordinarias de Espana 1810.1812 (compilacion de documentos), s.e., San Juan, 1969.

-Cornier López, Cantaliz, "La ley municipal de 1835. Retroceso político institucional y afianzamiento de la clase propieta. ria en el municipio de San Juan", tesis de maestría, Departamento de Historia-Universidad de Puerto Rico, Río Piedras, 1989.

-Cruz Monclova, Lidio, Historia de Puerto Rico (siglo XIX), Editorial Universitaria, Río Piedras, $5^{\text {a. }}$ ed., 1952.1979, 3 to mos, 6 vols.

-Cubano Iguina, Astrid, "Comercio y hegemonía social: los comerciantes de Arecibo, 1857-1887 ${ }^{n}$, tesis de maestría, Departamento de Historia-Universidad de Puerto Rico, Río Piedras, 1979.

_., "El estudio de las elites económicas y la política en Puerto Rico en el siglo XIX", Boletín del Centro de Investigaciones Históricas, núm. 4, 1988-1989.

El hilo en el laberinto. Claves de la lucha politica en Puerto Rico (siglo XIX), Ediciones Huracán, Río Piedras, 1990.

-, "Paz pública y propiedad territorial: la discusión sobre política agraria en Puerto Rico, 1880-1889", Boletín del Centro de Investtgaciones Históricas, núm. 5, 1990.

-Flores Collazo, Margarita, "Orden público y represión en el Puerto Rico del siglo
$\mathrm{XIX}^{n}$, tesis de maestría (inédita), Departamento de Historia-Universidad de Puerto Rico, Río Piedras, 1991.

-Gómez Acevedo, Labor, Organización y reglamentación del trabajo en el Puerto Rico del siglo XXX. (Propietarios y jornalenos), Instituto de Cultura Puertorriqueña, San Juan, 1970.

-González Vales, Luis E., Alejandro Ramirez y su tiempo. Ensayos de historia económica e institucional, Editorial Universitaria, Río Piedras, 1978.

-Náter Vázquez, Laura, "Los autonomismos: de la semilla al proyecto (1809. $18877^{n}$, tesis de maestría (inédita), Departamento de Historia-Universidad de Puerto Rico, Río Piedras, 1991.

-Ormaechea, Darío de, "Memoria acerca de la agricultura, el comercio y las rentas internas de la isla de Puerto Rico. Año $1847^{n}$, en Eugenio Fernández Méndez, Crónicas de Puerto Rico. Desde la conquista hasta nuestros dias (1493-1955), Editorial de la Universidad de Puerto Rico, Río Piedras, $2^{a}$ ed., 1981.

-Picó, Femando, Libertad y servidumbre en el Puerto Rico del siglo $\mathrm{x} x$, Ediciones Huracán, Río Piedras, 1981.

Historia general de Puerto Ri$c o$, Ediciones Huracán, $3^{\mathrm{a}}$ ed., revisada y aumentada, Río Piedras, 1986.

-Proyecto de instrucción para el gobierno económico-politico de las provincias de ultramar, Imprenta de don Tomás Albán y Compañía, Madrid, 1823.

-Ramos Mattei, Andrés, La hacienda azucanera. Su crecimiento y crisis en Puerto $R$ iCo (siglo XIX), CEREP, San Juan, $2^{\mathrm{a}}$ ed., 1986.

, La sociedad del azúcar en Puerto Rico: 1870-1910, Universidad de Puerto Rico, Río Piedras, 1988.

-Scarano, Francisco A., Puerto Rico. Cinco siglos de historia, McGraw.Hill, Colombia, 1993.

-Silvestrini, Blanca G. y María Dolores Luque de Sánchez, Historia de Puerto Rico: trayectoria de un pueblo, Cultural Puertorriqueña, Inc., San Juan, 1987. 